\title{
The Impact of Using Explicit/Implicit Vocabulary Teaching Strategies on Improving Students' Vocabulary and Reading Comprehension
}

\author{
Al-Mu'tassim A. Al-Darayseh \\ Al-Imam Mohammad Bin Saud University, Saudi Arabia
}

\begin{abstract}
This study aims at investigating the impact of a combination of both the explicit and implicit vocabulary teaching strategies on developing EFL learners' vocabulary size and improving their reading comprehension skills. The sample of the study consisted of 55 second-year students studying in the College of Economy at Al-Imam University. The two sections were randomly selected out of 10 sections studying English as a basic requirement in this college during the first semester of the academic year 2013/2014. The two sections were assigned to both experimental and control groups. A vocabulary and reading comprehension pre-test was given to both groups at the beginning of the study to get sure that were equivalent and homogenous. The experimental group was taught vocabulary and reading texts explicitly and implicitly, while the control group was taught in the traditional vocabulary teaching method. Two English instructors with similar qualifications and experiences taught the two groups for one complete semester. The same vocabulary and reading comprehension pre-test was given as a post-test at the end of the treatment. The gathered data out of the Pre-post Test were statistically analyzed, and the findings were obtained. The findings revealed significant differences between the control and experimental groups in favor of the experimental one. The combination of explicit and implicit vocabulary strategies has proved to be effective in increasing students' vocabulary size, and as a result, in improving their reading comprehension skills. The researcher reached some conclusions, implications and recommendations.
\end{abstract}

Index Terms-explicit/implicit vocabulary teaching strategy, traditional vocabulary teaching method, reading comprehension

\section{INTRODUCTION}

Improving EFL students' reading comprehension is a goal which every responsible teacher tries hard with his students to achieve. The mastery of reading comprehension skills is the key for students to get well with most content courses. Therefore, writers, educators and researchers have dealt with this matter seriously. In particular, they have investigated the relationship between vocabulary and reading comprehension, and they tried hard to find out the best techniques to improve EFL students' reading comprehension.

Writers and researchers have expressed several views and have reached several conclusions on the relationship between vocabulary and language skills in general, and between vocabulary and reading comprehension in particular. For instance, Neumann \& Dwyer (2009), states "The importance of vocabulary can be defined as "the words we must know to communicate effectively: words in speaking (expressive vocabulary) and words in listening (receptive vocabulary)" (p.385). Sedita (2005), asserts that "One of the oldest findings in educational research is the strong relationship between vocabulary knowledge and reading comprehension. He adds that word knowledge is crucial to reading comprehension and determines how well students will be able to comprehend the texts they read in middle and high school" (p.38). Chall \& Jacobs (2003), points out that "the correlation of word knowledge with reading comprehension indicates that if students do not adequately and steadily grow their vocabulary knowledge, their reading comprehension will be affected" (p.47). Cunningham \& Stanovich (1998), also says that students who do not understand some words in texts tend to have difficulty comprehending and learning from those texts. Hirsch (2003), goes further by saying that "Vocabulary experts agree that adequate reading comprehension depends on a person already knowing between 90 and 95 percent of the words in a text" (p.16). Camille L.Z, \& Fisher, P. (2005), clarify that "one area of particular significance to the curriculum is that of vocabulary and reading comprehension" (p.1). Dressler, C., August, D., Carlo, C., et al (2005), also found that "English language learners who experienced slow vocabulary development were less able to comprehend texts at the grade level than their English-only peers" (p.50). Wolley (2010), asserts that a particular problem for students with poor comprehension is that they have difficulty learning new vocabulary. Smith (1997) says that there is a common sense relationship between vocabulary and reading comprehension since messages which are composed of ideas are expressed in words. Wallace (2008) points out that difficulty in reading at the appropriate grade level is perhaps due to the a lack of sufficient vocabulary. BoulwareGooden, R., Suzanne Carreker,S., Ann Thornhill, A., et al (2007) clarifies that comprehension is the reason for reading, and vocabulary plays a significance role in comprehension. 
Different articles and studies have focused on the effect of teaching vocabulary implicitly or explicitly to improve students reading comprehension, while very few articles and studies have tackled the impact of combining both vocabulary teaching techniques on improving students' reading comprehension skills. Ellis (1994) claims that implicit vocabulary teaching and learning method involves indirect or incidental, whereas the explicit method involves direct or intentional. Greenwood \& Flannigan (2007) think that "90\% of the words that a student learns over the course of a year are without direct instruction. These words are learned through incidental contact" (p.249). Jenkins (2012) asserts that "By explicit instruction, we mean teaching where the instructor clearly outlines what the learning goals are for students, and offers clear, unambiguous explanations of the skills and information structures they are presenting. He also adds that by implicit instruction, we refer to teaching where the instruction does not outline such goals or makes such explanation overtly, but rather simply" (p.1).

To conclude, we can clearly say that selecting the correct or the most efficient technique or strategy to introduce vocabulary items is an integral factor in improving EFL students' reading comprehension.

\section{Location of the Study}

This study was administered in the College of Economy at Al-Imam Mohammad Bin Saud University located in Riyadh, the capital of Saudi Arabia. Al-Darayseh (2013), states "This university is one of the biggest and most prominent universities in Saudi Arabia. The population of this university is more than 25,000 Saudi students who join this university for graduate and postgraduate Studies. There are hundreds of foreign students who join this university to study Islamic religion and Arabic language. Al-Imam University teaches several human, applied, medical, admin, and religious majors. It has got several branches in big Saudi cities as well as intermediate and secondary Islamic institutes in major cities of Saudi Arabia, Ras Al-Khaimah, the USA, Indonesia, Malaysia, Djibouti and Japan" (p.424).

\section{Statement of the Problem}

Most English instructors complain that their students suffer a lot from being unable to comprehend reading texts because they lack the required size of vocabulary to understand the target texts. Therefore, Students are not successful in reading comprehension due to their deficiency in vocabulary. Unknown words hinder students from understanding the reading texts and the given questions as well. Therefore, it is very important to attempt and examine various vocabulary teaching techniques and strategies so as to find the most effective ones which may help a lot in developing students' vocabulary, and as a result, to improve their reading comprehension skills. Thus the purpose of this study is to investigate the effect of a combination of explicit and implicit vocabulary strategies on the development of EFL learners' vocabulary and improving their reading comprehension skills.

\section{Questions of the Study}

1. Are there any significant differences between the total mean scores of students in the experimental group and those in the control group attributed to the use of explicit/implicit vocabulary teaching strategies?

2. Are there any significant differences between students' reading comprehension mean scores in the experimental group and those in the control group attributed to the use of explicit/implicit vocabulary teaching strategies?

3. Are there any significant differences between students' vocabulary mean scores in the experimental group and those in the control group attributed to the use of explicit/implicit vocabulary teaching strategies?

4. Is there a significant relationship between the experimental group students' mean scores in reading comprehension and vocabulary?

\section{REVIEW OF RELATED LITERATURE}

Several researchers have investigated the effect of using different strategies and techniques to facilitate the vocabulary teaching/learning process, and as a result, to improve students' reading comprehension skills.

Mirzai (2012), compared "the effectiveness of Implicit Vocabulary Learning (IVL) through Extensive Reading with that of Explicit Vocabulary Learning (EVL) through activities requiring Deep-Level Cognitive Processing on the longterm vocabulary recall of 62 Iranian intermediate EFL learners. Quasi-experimental; the IVL and EVL, comprising 30 and 32. Prior to the treatment, both groups underwent a proficiency test namely, preliminary English Test ( PET), the IVL participants did regular 20 minutes in-class extensive reading. The EVL participants, on the other hand, were taught new vocabulary using activities which demanded deep-level cognitive processing. A pre-test prior to the treatment and post-test after the treatment were administered, both in the form of a standardized vocabulary test with three subtests meaning, preposition and collocation. Data analyses indicated significant improvement of both groups on the post test. Concerning the subtests, nevertheless while the EVL outperformed the IVL in meaning and preposition, the IVL did marginally better on the subtest of collocation" (p.3).

Gulcan and Cem (2013), "explored the relationship between second-language (L2) explicit/implicit knowledge sources, embedded in the declarative/procedural memory systems, and L2 working memory (WM) capacity. It further examines the relationships between L2 reading comprehension and L2 WM capacity as well as those between L2 reading comprehension and L2 explicit knowledge sources. Participants were late adult learners of English as an L2, with a relatively advanced level of English proficiency. They completed tests measuring their WM capacity, explicit knowledge, implicit knowledge, and L2 reading comprehension. Correlation analysis revealed significant relationship between L2 WM capacity and both explicit and implicit L2 knowledge. Exploratory factor analysis showed that explicit 
knowledge, WM capacity, and L2 reading comprehension loaded on a single factor, whereas implicit L2 knowledge formed an independent factor with no relationship to L2 reading" (p.13).

Hyso. and Tabaku (2011), conducted a research "with 80 first-year students studying English as their major in the University of Vlora and University of Tirana, Albania. The aim of this research was to give an overview of the benefits the students have about vocabulary learning, its direct teaching, its importance in university studies and of the vocabulary learning strategies used by them. The conclusions reached were that direct teaching of vocabulary in university context was important and lead to better text comprehension" (p.53).

Yali (2010), conducted a case study "to explore the role of reading in L2 vocabulary acquisition, and the effect of different vocabulary instructional techniques on the vocabulary learning of ESL students of different levels in Chinese universities. The results of the study reached the following finding: 1) Both instructional treatments resulted in significant gains in learners' receptive vocabulary knowledge, but the combination of the incidental and intentional learning instruction lead to greater vocabulary gains and better retention 2) Students' vocabulary size played a decisive role in acquiring the productive aspect of the vocabulary knowledge" (p.74).

Mihara (2011), "focused on two pre-reading strategies: vocabulary pre-teaching and comprehension question presentation. He examined the effects of the two reading strategies and discussed the relationship between students' English proficiency and their reading comprehension. The participants in the present study were asked to perform a prereading strategy, read a passage, and then answer comprehension questions. They read four passages altogether. Three weeks after they read the fourth passage, they were asked to answer a questionnaire. This study indicates that vocabulary pre-teaching is less effective for Japanese students, although students with higher English proficiency outperformed lower-level students regardless of which pre-reading strategy they used" (p.51).

Taboada (2011), "explored the extent to which two instructional frameworks (the Contextualized Vocabulary Instruction and the Intensified Vocabulary Instruction) influenced and supported the Fourth-grade English-language learners' reading comprehension and vocabulary acquisition. In the (CVI) framework, four reading comprehension strategies were integrated with two autonomy-supportive practices and implicit instruction of academic science vocabulary were used, while in the (IVI) framework, students experienced explicit instruction of academic vocabulary in relation to reading, without explicit strategy instruction or attention to autonomy supports. Results indicated that the IVI framework increased students' academic vocabulary even 3 weeks after the invention was over, whereas CVI benefited reading comprehension as well as autonomous learning in the classroom" (p.113).

To sum up, the previous review of related literature has clearly shown that researchers and educators have tried hard to find out the best techniques and strategies to teach vocabulary and reading comprehension. To the best knowledge of the researcher, no studies at the national level and very few ones at the international level have been conducted to investigate the impact of combining explicit and implicit vocabulary teaching strategies so as to improve EFL students' reading comprehension skills. Some researchers have investigated the effect of using either explicit or implicit vocabulary teaching strategy, and a result, to improve EFL students' reading comprehension skills, whereas they have rarely investigated the impact of combining both of these strategies. Therefore, this study is expected to be an effort in the right direction to investigate the influence of combining both of these strategies to introduce vocabulary items and to improve EFL students' reading comprehension.

\section{Methodology}

\section{Design of the Study}

The experimental design for this study was a quantitative design. Specifically, the design was a quasi-experimental Pretest-posttest experimental design which was used to investigate the effectiveness of using a combination of vocabulary implicit/explicit teaching strategies to develop students' vocabulary and to improve their reading comprehension.

\section{Sample of the Study}

Two parallel groups from the second-year students, majoring in economy at Al-Imam Mohammad Bin Saud University, Riyadh, Saudi Arabia participated in this study. There were 55 subjects in the two groups, ranging from 19 to 22 in age. The control group consisted of 28 students, and the experimental one consisted of 27 students.

\section{Instrument of the Study}

A vocabulary-reading comprehension Pre-posttest was used before commencing the treatment and at its end (see Appendices A and B).

\section{Validity of the Instruments}

To guarantee the validity of the vocabulary-reading comprehension pre-posttest that was prepared by the researcher, it was given to a group of TEFL specialists at Al-Imam University to examine their accuracy and adequacy. They The TEFL group consisted of five university professors who teach reading comprehension to English majors enrolled at the English college at the same university. Their comments and views were received, and the necessary modifications were made accordingly.

\section{Testing Stability:}

In order to verify the stability of the test, the researcher used the (Test R Test) which was applied on a sample, that was extracted from the original sample of the study, of 15 students and re-applied a week after on the same sample. The 
extracted correlation coefficient between the two applications reached (0.95) which indicates a significant value of the stability of the application.

Equality of Groups

To find out the equality of means and standard deviations of students' performance on the pre-test, the Independent Samples T-Test was applied. Table (1) shows that.

TABLE (1):

RESUltS OF INDEPENDENT SAMPLES T-TEST FOR STUDENTS' PERFORMANCE IN THE PRE-TEST BY THE STUDY SAMPLES.

\begin{tabular}{|c|c|c|c|c|c|c|}
\hline & Groups & Mean & S.D & $\mathbf{T}$ & DF & Sig. \\
\hline \multirow{2}{*}{ Students' Reading Comprehension } & control group & 10.69 & 4.99 & \multirow{2}{*}{0.64} & \multirow{2}{*}{55} & \multirow{2}{*}{0.52} \\
\hline & experimental group & 9.93 & 3.97 & & & \\
\hline \multirow{2}{*}{ Students' Vocabulary } & control group & 19.90 & 6.19 & \multirow{2}{*}{$1.63-$} & \multirow{2}{*}{55} & \multirow{2}{*}{0.10} \\
\hline & experimental group & 22.71 & 6.85 & & & \\
\hline \multirow{2}{*}{ Total } & control group & 10.00 & 5.46 & \multirow{2}{*}{$1.62-$} & \multirow{2}{*}{55} & \multirow{2}{*}{0.11} \\
\hline & experimental group & 12.79 & 7.43 & & & \\
\hline
\end{tabular}

Table (1) shows that there were no significant differences on the pre-test between experimental and control groups in relation to the students' size of vocabulary and reading comprehension, which means that students in both groups were equivalent.

Definition of Terms

Explicit/ Implicit Vocabulary Teaching Strategy

This includes a combination of explicit and implicit teaching strategies to teach the vocabulary items in certain reading texts. This combination includes the teaching of some key words explicitly (directly) by using different techniques such as giving definitions, using synonyms and antonyms, word collocations..etc. before asking students to read the assigned texts silently, and then to teach independent word-learning strategies which mainly depend on the included contextual clues.

Traditional Vocabulary Teaching Method

This method depends on listing and defining most new words, using English /Arabic translation dictionaries , and then asking them to memorize the meanings in English and in Arabic.

Vocabulary

Neumann \& Dwyer (2009), defines vocabulary can as "the words we must know to communicate effectively: words in speaking (expressive vocabulary) and words in listening (receptive vocabulary)” (p. 385).

\section{Reading Comprehension}

It is the ability to read a certain text, to process it skillfully and to understand its major and minor ideas.

\section{THE FINDINGS OF THE STUDY}

Question 1: Are there any significant differences between the total mean scores of students in the experimental group and those in the control group attributed to the use of vocabulary explicit/implicit teaching strategies?

To answer this question, descriptive statistical means and standard deviations for students' performance on the posttest were computed, and Independent Samples T-Test was applied. Table (2) shows that.

TABLE (2):

RESUlts OF INDEPENDENT SAMPLES T-TEST FOR STUDENTS' PERFORMANCE ON THE POST-TEST .

\begin{tabular}{|l|l|l|l|l|l|}
\hline Groups & Mean & S.D & T & DF & Sig. \\
\hline Control Group & 20.10 & 3.23 & \multirow{2}{*}{6.23} & 55 & \multirow{2}{*}{0.00} \\
\hline Experimental Group & 28.75 & 6.71 & & & \\
\hline
\end{tabular}

Table (2) shows that there were significant differences between students' means and standard deviations on the on the vocabulary-comprehension post-test since the T. value reached (-6.23), by Sig. (0.00). Through table (2), the results indicate there were significant differences between the control group and the experimental group in favor of the experimental one.

Question 2: Are there any significant differences between students' reading comprehension mean scores in the experimental group and those in the control group attributed to the use of vocabulary explicit/implicit teaching strategies?

To answer this question, descriptive statistical means and standard deviations for students' performance on the reading comprehension post-test by the control and experimental groups were computed. For this purpose, the Independent Samples T-Test was applied, and the results are shown in Table (3).

TABLE (3):

RESUlt OF INDEPENDENT SAMPLES T-TEST FOR STUDENTS' PERFORMANCE ON THE READING COMPREHENSION POST-TEST BY EXPERIMENTAL AND CONTROL GROUPS.

\begin{tabular}{|l|l|l|l|l|l|}
\hline Groups & Mean & S.D & T & DF & Sig. \\
\hline Control Group & 10.59 & 4.63 & \multirow{2}{*}{-3.10} & 55 & \multirow{2}{*}{0.00} \\
\hline Experimental Group & 15.07 & 6.19 & & & \\
\hline
\end{tabular}


Table (3) shows that there were significant differences on students' performance on the reading comprehension posttest since the T. value reached (-3.10), by Sig. (0.00). Table (3) indicates significant differences between control group and experimental group in favor of the experimental one.

Question 3: Are there any significant differences between students' vocabulary mean scores in the experimental group and those in the control group attributed to the use of vocabulary explicit/implicit teaching strategies?

To answer this question descriptive statistical means and standard deviations for students' performance on the vocabulary post-test by the control and experimental groups were computed, Independent Samples T-Test was applied, and the results are shown in Table (4).

TABLE (4):

RESULT OF INDEPENDENT SAMPLES T-TEST FOR STUDENTS' PERFORMANCE ON THE VOCABULARY

POST-TEST BY THE CONTROL AND EXPERIMENTAL GROUPS.
\begin{tabular}{|l|l|l|l|l|l|}
\hline Groups & Mean & S.D & T & DF & Sig. \\
\hline Control Group & 8.97 & 3.55 & \multirow{2}{*}{-2.69} & \multirow{2}{*}{55} & \multirow{2}{*}{0.00} \\
\hline Experimental Group & 12.71 & 6.57 & & & \\
\hline
\end{tabular}

Table (4) shows that there were significant differences in students' performance on the vocabulary post-test since the T. value reached (-2.69), by Sig. (0.00). Table (4) indicates that there were significant differences between the control group and the experimental groups in favor of the experimental one.

Question 4: Is there a significant relationship between the experimental group students' mean scores in reading comprehension and vocabulary?

To answer this question, Pearson Correlation between the experimental group students' mean scores in vocabulary and reading comprehension was computed. The results are shown in Table (5).

TABLE (5):

PEARSON CORRELATION BETWEEN EXPERIMENTAL STUDENTS' MEAN SCORES IN READING AND VOCABULARY

\begin{tabular}{|l|l|l|}
\hline & Pearson correlation & Sig. \\
\hline Vocabulary & \multirow{2}{*}{0.84} & 0.00 \\
\cline { 1 - 1 } Reading & & 0.00 \\
\hline
\end{tabular}

Table (5) shows that the correlation coefficient between the experimental group students' mean scores in reading and vocabulary reached $(0.84)$ by Sig. $(0.00)$. This indicates that there was a significant relationship between the experimental group students' mean scores in reading comprehension and vocabulary.

\section{DisCUSSION OF THE FINDINGS}

Concerning the first question of the study about whether there are any significant differences between the means of students in the experimental group and the students' means in the control group attributed to the using a combination of explicit/implicit vocabulary teaching strategies, the findings of the study indicated that there were significant differences between the mean scores of students in the experimental group and those in the control group in favor of the experimental group attributed to the use of explicit/implicit vocabulary teaching strategies. It seems that the combination between the explicit and implicit vocabulary teaching strategies has led to a very good progress in the total EFL students' language performance. Introducing the meanings of the key words prior to starting reading the assigned text helped students a lot in getting good background knowledge about the topic of the reading text and in understanding the main ideas of this text. In addition, giving students the chance to improve their word-meaning attack skill through the reading text added a lot to their vocabulary size and to their skills in comprehending the assigned reading passages. In general, using both explicit and implicit strategies together in teaching vocabulary and reading comprehension has proved to be more effective than using only one or depending on the traditional method which is mainly based on defining new words and showing their meanings prior to reading a new text or having students look words up in a dictionary, finding the nearest equivalents which are often used in order to help them learn these new words and memorize them in word lists.

With respect to the second question of the study about whether there are any significant differences between students' reading comprehension mean scores in the experimental group and those in the control group attributed to the use of vocabulary explicit/implicit instruction, the results of the study showed significant differences between students' reading comprehension mean scores in the experimental group and those in the control group in favor of the experimental one. This means that the effective utilization of explicit/implicit vocabulary instruction has contributed a lot in getting the meanings of the difficult words and expressions included in the reading comprehension text, and as a result, in improving their comprehension skills especially skimming and scanning. This result is in line with the findings of Gulcan (2013).

With regard to the third question of the study about whether there are any significant differences between students' vocabulary mean scores in the experimental group and those in the control group attributed to the use of explicit/implicit vocabulary teaching strategies, the findings of the study also indicated significant differences between 
students' vocabulary mean scores in the experimental group and those in the control group in favor of the experimental one. This is really justified, since students passed through two stages to study the vocabulary items. The first stage was directly done by the teacher before reading the assigned text by presenting the meanings of the key words and expressions explicitly prior to tackling the reading text. The second stage occurred when students were asked to tackle more words and expressions implied in the reading text. Dealing with vocabulary explicitly and implicitly has actually improved students' vocabulary retention, and as a result, has greatly improved their grades on the post-test exam. This result is in harmony with the findings of Mirzai (2012) and Yali (2013).

Concerning the fourth question of the study, the results showed that there was a significant relationship between the experimental group students' mean scores in reading comprehension and theirs in vocabulary. This finding could be logical and justified since vocabulary is one of the main cornerstones of reading comprehension skills. EFL students usually face hardships and difficulties in comprehending even simple texts because of their vocabulary deficiency. The use of both explicit and implicit vocabulary teaching strategies has given students enough chance to practice and learn new vocabulary items and has greatly influenced students' vocabulary size, and as a result, has reflected positively upon their skills in reading comprehension.

In general, the findings of this study tie up with the theoretical assumptions and opinions cited in the introduction of this study. These findings really present clear evidence that the combination of both explicit and implicit vocabulary teaching strategies has proved to be a very effective method in developing students' vocabulary items and improving their reading comprehension as well.

\section{CONCLUSIONS, IMPLICATIONS AND RECOMMENDATIONS}

In the light of the present study, the researcher reached the following conclusions, implications and recommendations.

- Teachers should try hard to vary their vocabulary teaching techniques and strategies and should avoid traditional ones which mainly depend on memorization.

- Students should be given enough chance to develop their meaning- attack skills by utilizing the implicit vocabulary teaching strategy effectively.

- The utilization of the explicit vocabulary teaching strategy should also be given enough attention so as to provide students with background knowledge about the assigned texts and to facilitate students' reading comprehension.

- Students should be always encouraged to utilize the clues implied in the reading texts so as to develop their general language proficiency and to improve their reading comprehension skills in particular.

- Arabic translation of new vocabulary items should always be avoided. There are various teaching techniques which should effectively be used. Arabic translation only be used as the last solution.

- More studies are recommended to investigate the effectiveness of other innovative vocabulary teaching strategies and techniques.

\section{Appendix A. Pre-post Test: Vocabulary and Reading Comprehension}

\section{Vocabulary:}

\section{Question I: Read the following sentences and choose the correct answers. (10 marks)}

1. These trousers are a bit tight around my.
a. back
b. stomach
c. wrist
d. waist

2. Ahmad b. duvet

c. socket

d. vas

3. I spilled the juice when I was It.
a. pouring
b. chopping
c. peeling
d. baking

4. The potatoes are........................'ll put them back in the oven.
a. overcooked
b. burnt
c. tender
d. underdone

5. "I'll tidy the kitchen if you clean the car." "OK. It's a
a. bargain
b. surgery
c. discount
d. receipt

6. I am very busy. Could we....................the meeting for a few days?
a. aisle
b. terminus
c. delay
d. way out

7. The weather. .said it was going to rain later today.
a. comedy
b. forecast
c. horror
d. Quiz

8. I got a $20 \%$ on every computer I sell.
a. commission
b. mean
c. saving
d. refund

9. Do you want to go on the school. to Medina this year?
a. compartment
b. conductor
c. trip
d. journey

10. He pulled a big fat.

a. bracelet

b. cheque book stuffed with bank notes.

\section{Question II. a: Decide if each of the following statements is true or false. (5 marks)}

1. Sole is the bottom part of a foot or shoe which touches the ground. 
2. "Earn" means receiving money as payment for work that you do.

3. Documentary is a TV program that gives facts about many subjects.

4. "Queue" means a line of people, standing or in cars, waiting for food.

5. A person whose job is to make bread and cake for sale is a baker.

$\begin{array}{ll}\mathrm{T} & \mathrm{F} \\ \mathrm{T} & \mathrm{F} \\ \mathrm{T} & \mathrm{F} \\ \mathrm{T} & \mathrm{F}\end{array}$

Question II. b: Match the words in column A. with their meanings in column B. (5 marks)
1. optician
2. dubbed
3. terminus
4. disgusting
5. generous
a............ willing to give money, help, kindness, etc.
b. ........... provide with a soundtrack of foreign language
c............. extremely unpleasant or unacceptable
d............. the last stop or the station at the end of a bus railway route
e.............someone who examines people's eyes and sells glasses

\section{Question III. Choose the correct words. (5 marks)}

\begin{tabular}{|l|l|l|l|l|}
\hline A bottle & A tub & A bar & A loaf & A can \\
\hline
\end{tabular}

1.

2. of ice cream. ...of bread

3.

4. of chocolate.

5 .

\section{Reading Comprehension:}

Question IV: Scan the passage below and then put a circle around the correct answer. (10 marks)

Dentists always ask questions when it is impossible for you to answer. My dentist had just pulled out one of my teeth and had told me to rest for a while. I tried to say something, but my mouth was full of cotton-wool. He knew I collected birds' eggs and asked me whether my collection was growing. He then asked me how my brother was and whether I liked my new job in London. In answer to these questions, I either nodded or made strange noises. Meanwhile, my tongue was busy searching out the hole where the tooth had been. I suddenly felt very worried, but could not say anything. When the dentist at last removed the cotton-wool from my mouth, I was able to tell him that he had pulled the wrong one.

1. The underlined word "searching" means.
a. pulling
b. collecting
c. looking for
d. making

2. The dentist asked the patient about
a. his brother
b. his job
c. his interests d. his university

3. Because. was in his mouth, the patient couldn't speak.
a. a tooth
b. cotton-wool
c. his tongue
d. an egg

4. The patient was moving his ..to find the hole in his mouth.
a. tongue
b. teeth
c. mouth
d. cotton

5. The mistake the doctor made was..
a. pulling the correct teeth
b. collecting birds' eggs
c. making strange noise
d. pulling the wrong tooth

Question V: Read the text again, and then decide if each of the following statements is True or False. (5 marks)

1. Dentists usually ask questions when it is possible for the patient to answer.

2. The patient's mouth was full of food.

3. The dentist asked the patient about his brother.

4. The patient's job was in Riyadh.

5. The dentist had pulled the correct tooth.

Question VI: Read the text below, and then answer the questions that follow. [10 marks]

The parents decided they should have fewer children so they could give each one a good life. They thought it was important for the mother to spend as much time as possible with her children. Before, all the family worked together at home. After 1800 more fathers worked outside the home for money. Mothers stayed home and had greater control of the home and children. Most homes did not produce anything. Home was a safe, warm place for the father after work and for the mother and small children all day. The other relatives were still important, but they were separated more than before.

1. Why did the parents decide to have fewer children?

2. How did the roles of mothers and fathers change after 1800 ?

3. The underlined pronoun "they" refers to.

4. How has the relationship with the relatives become?

5. Find a word in the text which means the same as make?

ApPendix B. The Answer Key of the Pre-Post Test: Vocabulary AND READING COMPREHENSION

\section{Vocabulary:}


Question I: Read the following sentences and choose the correct answers. (10 marks)

1. These trousers are a bit tight around my....
a. back
b. stomach
c. wrist
d. waist

2. Ahmad forgot to plug the television into the wall.
a. cable
b. duvet
c. socket
d. vas

3. I spilled the juice when I was It.
a. pouring
b. chopping
c. peeling
d. baking

4. The potatoes are ..I'll put them back in the oven.
a. overcooked
b. burnt
c. tender
d. underdone

5. "I'll tidy the kitchen if you clean the car." "OK. It's a
a. bargain
b. surgery
c. discount
d. receipt

6. I am very busy. Could we. the meeting for a few days?
a. aisle
b. terminus
c. delay
d. way out

7. The weather. .. said it was going to rain later today.
a. comedy
b. forecast
c. horror
d. Quiz

8. I got a $20 \%$ on every computer I sell.
a. commission
b. mean
c. saving
d. refund

9. Do you want to go on the school.

c. trip $\quad$ d. journey
a. compartment
b. conductor
d. journey
a. bracelet
b. cheque book
c. umbrella
d. wallet

Question II.a: Decide if each of the following statements is true or false. (5 marks)

1. Sole is the bottom part of a foot or shoe which touches the ground.

2. "Earn" means receiving money as payment for work that you do.

3. Documentary is a TV program that gives facts about many subjects.

4. "Queue" means a line of people, standing or in cars, waiting for food.

5. A person whose job is to make bread and cake for sale is a baker.

$\begin{array}{cc}\mathbf{T} & \mathrm{F} \\ \mathbf{T} & \mathrm{F} \\ \mathrm{T} & \mathbf{F} \\ \mathbf{T} & \mathrm{F} \\ \mathbf{T} & \mathrm{F}\end{array}$

Question II. b: Match the words in column A. with their meanings in column B. (5 marks)
1. optician
a.....5....... willing to give money, help, kindness, etc.
2. terminus
3. dubbed
b. ............ provide with a soundtrack of foreign language
4. disgusting
c.....4.........extremely unpleasant or unacceptable
5. generous
d....2....... the last stop or the station at the end of a bus railway route
e.....1........someone who examines people's eyes and sells glasses

Question III. Choose the correct words. (5 marks)

\begin{tabular}{|l|l|l|l|l|}
\hline A bottle & A tub & A bar & A loaf & A can \\
\hline
\end{tabular}

1. ..................A tub

2. ................. A loaf

of ice cream.

3. .................. A bar

of brad

A can

of chocolate.

4

A bottle

...of cola.

Reading Comprehension:

Question IV: Scan the passage below and then put a circle around the correct answer. (10 marks)

Dentists always ask questions when it is impossible for you to answer. My dentist had just pulled out one of my teeth and had told me to rest for a while. I tried to say something, but my mouth was full of cotton-wool. He knew I collected birds' eggs and asked me whether my collection was growing. He then asked me how my brother was and whether I liked my new job in London. In answer to these questions, I either nodded or made strange noises. Meanwhile, my tongue was busy searching out the hole where the tooth had been. I suddenly felt very worried, but could not say anything. When the dentist at last removed the cotton-wool from my mouth, I was able to tell him that he had pulled the wrong one.

1. The underlined word "searching" means.
a. pulling
b. collecting
c. looking for
d. making

2. The dentist asked the patient about.........................
a. his brother
b. his job
c. his interests d. his university

3. Because. ..was in his mouth, the patient couldn't speak.
a. a tooth
b. cotton-wool
c. his tongue
d. an egg

4. The patient was moving his....................to find the hole in his mouth.
a. tongue
b. teeth
c. mouth
d. cotton

5. The mistake the doctor made was
a. pulling the correct teeth
b. collecting birds' eggs 


\section{c. making strange noise d. pulling the wrong tooth}

Question V: Read the text again, and then decide if each of the following statements is True or False. (5 marks)

1. Dentists usually ask questions when it is possible for the patient to answer.

2. The patient's mouth was full of food.

3. The dentist asked the patient about his brother.

4. The patient's job was in Riyadh.

5. The dentist had pulled the correct tooth.

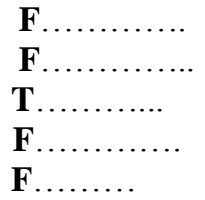

Question VI: Read the text below, and then answer the questions that follow. [10 marks]

The parents decided they should have fewer children so that they could give each one a good life. They thought it was important for the mother to spend as much time as possible with her children. Before, all the family worked together at home. After 1800 more fathers worked outside the home for money. Mothers stayed home and had greater control of the home and children. Most homes did not produce anything. Home was a safe, warm place for the father after work and for the mother and small children all day. The other relatives were still important, but they were separated more than before.

1. Why did the parents decide to have fewer children?

to give each one a good life

2. How did the roles of mothers and fathers change after 1800 ?

More fathers worked outside the home for money. Mothers stayed home and had greater control of the home and children.

3. The underlined pronoun "they" refers to

the parents

4. How has the relationship with the relatives become?

The other relatives were still important, but they were separated more than before.

5. Find a word in the text which means the same as make?

produce

\section{REFERENCES}

[1] Al-Darayseh, A. A. (2013). Activation of Using English Dictionaries by English Majors at Al-Imam University: Uses, Difficulties, and Types of Used Dictionaries. Theory and Practice in Language Studies, Vol. 3, No 3 (2013), 423-429.

[2] Boulware-Gooden, R., Suzanne Carreker,S., Ann Thornhill, A., et al. (2007). Instruction of Metacognitive Strategies Enhances Reading Comprehension and Vocabulary Achievement of Third Grade Students. Reading Teacher, v61 n1 p70-77.

[3] Camille L.Z, \& Fisher, P. (2005), Integrated Vocabulary Instruction: Meeting the Needs of Diverse Learners in Grades K-5, Retrieved from http://www.colorinclorado.org/article/1289 26-12-2013.

[4] Chall, J.s. \& Jacobs, V. A. (2003). Poor children's fourth-grade slump. American Educator, American Federation of Teachers.

[5] Cuningham, A. E. \& Stanovich, K. E. (1998). What Reading Does for the Mind. American Educator, Spring/Summer, 8-17.

[6] Dressler, C., August, D., Carlo, C., et al. (2005). The critical role of vocabulary development for English language learners. Learning Disabilities Research and Practice, 20, 1, 50-57.

[7] Ellis, N., C. (1994). Vocabulary acquisition: The implicit ins and outs of explicit cognitive mediation. Implicit and explicit learning of languages (pp. 211-282). London: Academic Press.

[8] Greenwood, S, C. \& Flannigan, K. (2007). Overlapping Vocabulary and Comprehension: Context clues compliment semantic gradients. Reading Teacher, 61(3), 249-254.

[9] Gulcan, E and Cem, A. (2013). The explicit/implicit knowledge distinction for second-language reading comprehension. Applied Psycholinguistics, Vol. 34 Issue 4, p727-p753

[10] Hirsch, E.D. (2003). Reading comprehension requires knowledge - of words and the world: Scientific insights into the fourthgrade slump and the nation's stagnant comprehension scores. American Educator, American Federation of Teachers.

[11] Hyso, K. and Tabaku, E. (2011). Importance of Vocabulary Teaching to Advanced Foreign Language Students in Improving Reading Comprehension. Problems of Education in the $21^{\text {st }}$ Century, 2011, Vol, 29, p53-62.

[12] Jenkins, Bill. (2012). Implicit vs. Explicit Instruction: Which is Better for Word Learning? Retrieved from http://www.scilearn.com/blog/implicit-vs-explicit-instruction-word-learning.php 26-12-2013.

[13] Mihara, K. (2011). Effects of Pre-Reading Strategies on EFL/ESL Reading Comprehension. TESL Canada Journal, v28 n2 p51-73.

[14] Mirzai, M. (2012). Implicit vs. Explicit Vocabulary Learning: Which Approach Serves Long-term Recall Better? 3L; Language, Linguistics and Literature, The Southeast Asian Journal of English Language Studies, 18 (2). pp. 1-12.

[15] Neuman, S. B., \& Dwyer, J. (2009). Missing in action: Vocabulary instruction in pre-K. The Reading Teacher, 62(5), 384-392.

[16] Sedita, Joan. (2005), Effective Vocabulary Instruction. “Insights on Learning Disabilities" 2(1) 33-45.

[17] Smith, Carl (1997). Vocabulary Instruction and Reading, Retrieved from ERIC database, (EDO-CS-97-07).

[18] Taboada. (2011). Developing Reading Comprehension and Academic Vocabulary for English Language Learners Through Science Content: A Formative Experiment. Reading Psychology Vol. 32 Issue 2, p113-157.

[19] Yali,G. (2010). Vocabulary Acquisition Through Reading Incidental Learning and Intentional Learning. Chinese Journal of Applied Linguistics Vol. 33 Issue 1, p74.

[20] Wallace, C. (2008). Vocabulary: The Key to Teaching English Language Learners to Read. Education Digest: Essential Readings Condensed for Quick Review, v73 n9 p36-39.

[21] Woolley, Gary. (2010). A Multiple Strategy Framework Supporting Vocabulary Development for Students with Deficits. A Australian Journal of Special Education, v34 n2 119-132. 


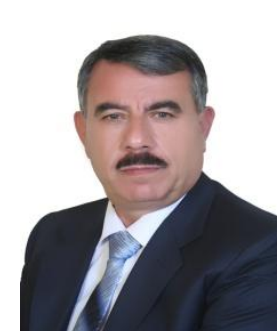

Al-Mu'tassim A. Al-Darayseh, born in Jericho, Jordan in 1956, holds a Ph.D. degree in TEFL from Arab Amman University, Amman, Jordan in 2003, an M.A. in TEFL from Yarmouk University, Irbid, Jordan in 1997.

He is currently an assistant professor at Al-Imam Mohammad Bin Saud University, Saudi Arabia. He has already published two research papers, the first one is entitled: "The Effect of Using the Whole Language Approach on Improving English Majors' Writing Ability at Jerash Private University", and the second is entitled: "The Relationship between Jerash University English Majors' Test Strategies and Their Academic Achievement". His research interests include teaching and testing issues, translation and ESP matters.

Dr. Al-Darayseh has worked in several curriculum and instruction projects and workshops for the Ministry of Education and Higher Studies in Jordan. 